Original Article

\title{
Continuous Paravertebral Analgesia versus Continuous Epidural Analgesia after Video- Assisted Thoracoscopic Lobectomy for Lung Cancer: A Randomized Controlled Trial
}

\author{
Jielan Lai, MD, ${ }^{*}, 1,2$ Dongrong Situ, MD, ${ }^{*}, 1,3,4$ Manxiu Xie, MD, ${ }^{1,2}$ Ping Yu, MD, ${ }^{1,2}$ \\ Junchao Wang, MD, ${ }^{1,2}$ Hao Long, MD, ${ }^{1,3,4}$ and Renchun Lai, MD ${ }^{1,2}$
}

\begin{abstract}
Background: Whether continuous thoracic epidural analgesia (TEA) and continuous paravertebral block (PVB) have similar analgesic effects in patients undergoing videoassisted thoracic surgery (VATS) lobectomy was compared in this study.

Methods: In all, 86 patients undergoing VATS lobectomy were enrolled in the prospective, randomized clinical trial. Group E received TEA. Group P received PVB. The primary endpoint was postoperative 24-hour visual rating scale (VAS) on coughing. Side effects and postoperative complications were also analyzed.

Results: Pain scores at rest or on coughing at 24 and $48 \mathrm{~h}$ postoperatively were significantly lower in group $E$ than in group $P(P<0.05)$. At 24 h postoperatively, more patients in group $E$ suffered from vomiting $(32.6 \%$ vs $11.6 \%, P=\mathbf{0 . 0 1 9})$, dizziness $(55.8 \%$ vs $12.9 \%, P=0.009)$, pruritus $(27.9 \%$ vs $2.3 \%, P=0.002)$, and hypotension $(32.6 \%$ vs $4.7 \%$, $P=0.002)$ than those in group $P$. Patients in group $E$ were more satisfied $(P=0.047)$. Four patients in group $P$ and two patients in group $E$ suffered from pulmonary complications $(P>0.05)$. The length of hospital and intensive care unit (ICU) stays were not significantly different.

Conclusions: Though TEA has more adverse events than PVB, it may be superior to PVB in patients undergoing VATS lobectomy.
\end{abstract}

Keywords: paravertebral analgesia, epidural analgesia, video-assisted thoracoscopic surgery, lobectomy

${ }^{1}$ Collaborative Innovation Center for Cancer Medicine, State Key Laboratory of Oncology in South China, Sun Yat-Sen University Cancer Center, Guangzhou, China

${ }^{2}$ Department of Anesthesiology, Sun Yat-Sen University Cancer Center, Guangzhou, China

${ }^{3}$ Lung Cancer Research Institute, Sun Yat-sen University, Guangzhou, China

${ }^{4}$ Department of Thoracic Surgery, Sun Yat-Sen University Cancer Center, Guangzhou, China

Received: September 1, 2020; Accepted: November 3, 2020 Corresponding author: Lai Renchun. Collaborative Innovation Center for Cancer Medicine, State Key Laboratory of Oncology in South China, Sun Yat-Sen University Cancer Center, 651 Dongfeng Road East, Guangzhou, Guangdong 510060, China

Email: lairch@sysucc.org.cn
*Authors, Jielan Lai and Dongrong Situ, contributed equally to this work.

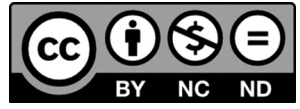

This work is licensed under a Creative Commons Attribution-NonCommercial-

NoDerivatives International License.

(C)2021 The Editorial Committee of Annals of Thoracic and Cardiovascular Surgery 
Lai J, et al.

\section{Introduction}

Recently, video-assisted thoracic surgery (VATS) has been increasingly used as an alternative to thoracotomy for lobectomy in the treatment of early-stage non-smallcell lung cancer. VATS is associated with less postoperative pain and better quality of life than anterolateral thoracotomy for the first year after surgery. ${ }^{1)}$ However, some patients still suffer from acute pain after VATS lobectomy, and the incidence of chronic pain has been reported to be as high as 30\%., ${ }^{2,3)}$ Pain control after VATS lobectomy is a contemporary question.

Thoracic epidural analgesia (TEA) is generally considered the gold standard analgesia after thoracotomy not only for its efficient pain relief but also for many other beneficial effects. ${ }^{4)}$ Paravertebral block (PVB) shows efficacy for pain management after VATS.5,6) However, some other studies have reported different results. ${ }^{7)}$ Only a few existing studies have compared PVB analgesic effects with epidural analgesia after VATS lobectomy. ${ }^{8,9)}$ Based on the few publications available in the literature, it is difficult to determine the superiority of any type of anesthesia for VATS lobectomy.

There are three methods used to locate the paravertebral space for catheter insertion: a blind anesthetic approach, ${ }^{10)}$ during surgery, ${ }^{11)}$ and an ultrasound-guided PVB approach. ${ }^{12)}$ The efficacy of PVB depends on accurate catheter placement. Other studies have shown the efficacy of paravertebral analgesia during surgery. ${ }^{13,14)}$ The aim of this study was to compare the analgesia efficacy and side effects of continuous paravertebral analgesia and continuous epidural analgesia for postoperative pain after VATS lobectomy.

\section{Methods}

This was a prospective randomized study performed between November 2017 and December 2018 at the Sun Yat-sen University Cancer Center. The institutional Review Board approved the study, and the study was registered at www.chictr.org.cn (ChiCTR-INR-17012928). Each patient provided written informed consent for participation. Consecutive patients undergoing VATS lobectomy for lung cancer were screened for inclusion. Eligible patients were randomly allocated into the continuous PVB group (group P) or the continuous TEA group (group E). The following inclusion criteria were applied: patients aged $18-80$ years old who were undergoing VATS lobectomy, American
Society of Anesthesiologists (ASA) physical status class I-III, an understanding of the principle of visual rating scale (VAS) pain assessment and no chronic pain. The exclusion criteria were as follows: patients who were on anticoagulation, patients taking opioids for greater than three weeks prior to surgery, patients with a contraindication to regional anesthesia such as infection close to the site of puncture, allergy to local anesthetics, and those with a history of chronic pain, severe cardiovascular disease, liver or renal insufficiency, a change in surgery type, conversion of VATS to thoracotomy, accidental catheter slipping, and patient refusal. Randomization was performed using a computer-generated randomization sequence by an investigator not involved in patient care or perioperative assessment.

\section{Anesthesia and surgery procedure}

No premedication was administered. All patients had standardized anesthetic delivery and postoperative pain control. Induction anesthesia included dexmedetomidine $0.5 \mu \mathrm{g} / \mathrm{kg}$, propofol $1.5 \mathrm{mg} / \mathrm{kg}$, sufentanil $0.5 \mu \mathrm{g} / \mathrm{kg}$, and cisatracurium $0.15 \mathrm{mg} / \mathrm{kg}$. Intubation was performed using a double-lumen endobronchial tube. Anesthesia was maintained with sevoflurane and remifentanil. All patients received $0.25 \mathrm{mg}$ of intravenous palonosetron by the end of the surgery. VATS lobectomy was performed by Dr. Long Hao's surgical group. During the VATS, we used a slightly modified version of the fourport technique. ${ }^{15)}$ In short, a $10 \mathrm{~mm}$ incision with a trocar was made in the seventh or eighth intercostal space in the mid-axillary line. About $4 \mathrm{~cm}$ incision was made between the fourth or fifth ribs. Two 10-15 mm incisions without trocars were made below the tip of the inferior scapular angle and near the rib curvature. After the surgery was finished, one or two chest drain tubes were placed.

\section{Catheter insertion procedure}

After VATS lobectomy, paravertebral catheters were placed by the surgeon under sterile conditions upon completion of surgery, as described by Fibla et al. ${ }^{16)}$ In short, the point of percutaneous puncture is about 10 $\mathrm{cm}$ away from the midline. $18 \mathrm{~g}$ of Tuohy needle passed through the chest wall vertically until the tip of the needle was close to the paravertebral pleura. $20 \mathrm{~mL}$ normal saline was given to form a detachment bag. Under the direct control of the surgeon, the catheter was inserted into the paravertebral space of $10 \mathrm{~cm}$. After suction, there was no blood and cerebrospinal fluid reflux. $4 \mathrm{~mL}$ of $2 \%$ lidocaine containing $5 \mu \mathrm{g} / \mathrm{mL}$ epinephrine was 
injected through the catheter to confirm the correct position.

The patient was given epidural puncture and catheterization under conscious local anesthesia. T7-8 was selected as the puncture point. Under local anesthesia of $2 \%$ lidocaine $1 \mathrm{~mL}$, the puncture was performed with a $17 \mathrm{G}$ Tuohy puncture needle. The position of epidural space was determined by resistance loss method. The epidural catheter was inserted into the epidural space about $4-5 \mathrm{~cm} .3 \mathrm{~mL}$ test dose of $1.5 \%$ lidocaine confirmed that the catheter position was correct.

\section{Postoperative analgesia management and patient as- sessment}

The epidural infusion consisted of ropivacaine $0.15 \%$ with $6 \mathrm{mcg} / \mathrm{mL}$ of hydromorphone and was administered via a pump (Opon, Jiangsu aipeng Medical Technology Co., Ltd, Nantong, China) starting at $2 \mathrm{~mL} / \mathrm{h}$ for $48 \mathrm{~h}$ postoperatively. Patients in the paravertebral group received an initial bolus of $0.5 \%$ ropivacaine $0.1 \mathrm{~mL} / \mathrm{kg}$ and then $0.1 \mathrm{~mL} / \mathrm{kg} / \mathrm{h}$ infusion for $48 \mathrm{~h}$ postoperatively. All patients received parecoxib $40 \mathrm{mg}$ before the incision followed by parecoxib $40 \mathrm{mg}$ every $12 \mathrm{~h}$ for 2 postoperative days. All patients also benefited from IV patient controlled analgesia (PCA) of oxycodone $50 \mathrm{mg}$ and palonosetron $0.075 \mathrm{mg}$ mixed with normal saline to a total volume of $100 \mathrm{~mL}$. The disposable PCA device was set to deliver no background infusion and $2 \mathrm{~mL}$ on-demand bolus with a lockout time of $5 \mathrm{~min}$. The postoperative care was the same for all the patients.

In the PACU, patients rated their pain at rest and on coughing using an 11-point VAS scale $(0=$ no pain, $10=$ worst imaginable pain). Patients in the PACU were assessed for pain every hour and treated with intravenous oxycodone when the pain score at rest was $>4$ or upon patient request. Pain was assessed using VAS, and pain scores were obtained twice per day by an investigator. The scores were recorded for the first 3 days postoperatively. If severe nausea or vomiting occurred, patients received $10 \mathrm{mg}$ metoclopramide. If severe vomiting did not improve despite pharmacological treatment or if severe dizziness or severe pruritus occurred, PCA was stopped temporarily. PCA was restarted after these symptoms subsided. Adverse effects, such as hypotension, postoperative nausea and vomiting (PONV), pruritus, dizziness, and postoperative pulmonary complications such as atelectasis, pneumonia, acute lung injury (ALI), and acute respiratory distress syndrome (ARDS), were recorded. The following parameters were also recorded: total remifentanil dose, anesthesia time, duration of surgery, the total amount of PCA oxycodone used, chest tube indwelling time, length of intensive care unit (ICU) stay, and length of hospital stay. Another investigator blinded to the group allocation collected all outcome and perioperative data. The presence of adverse events each day was noted in the patient's chart. Patient satisfaction was defined as $1=$ very satisfied, $2=$ satisfied, 3 = fair, and $4=$ dissatisfied.

\section{Outcomes}

The primary endpoints were $24 \mathrm{~h}$ postoperative pain on coughing. Secondary endpoints were $24 \mathrm{~h}$ postoperative pain at rest, 0 (at PACU), 2, 6, 48, and $72 \mathrm{~h}$ postoperative pain at rest and on coughing, cumulative oxycodone consumption and adverse effects (nausea, vomiting, dizziness, and pruritus), and patient satisfaction.

\section{Statistical analysis}

Collected data were subject to statistical analysis performed with the use of SPSS package 22.0 (SPSS Inc., Chicago IL, USA). The clinically significant VAS difference of $14 \mathrm{~mm}$ was accepted for sample size calculations. In the pilot study, the standard deviation of $24 \mathrm{~h}$ dynamic VAS was $22.5 \mathrm{~mm}$. Using these data, we determined that we would need 86 patients to achieve $90 \%$ power with $5 \%$ alpha. Each group should have included a minimum of 43 patients. We assumed that $10 \%$ would be lost to follow-up. Data are presented as the mean \pm standard deviation, mean (CI), median (interquartile range), or number (\%). Groups with normally distributed data were compared with an independent t-test, non-normally distributed data were compared with the MannWhiney U test, and categorical variables were compared with the ${ }^{2}$ test or Fisher's exact test. Changes in the pain severity in both groups were analyzed using a general linear model $(\mathrm{GLM})$ with repeated measures. $P$ values were not adjusted for multiple comparisons and should be interpreted cautiously. $P<0.05$ was considered statistically significant.

\section{Results}

A flow chart of the trial process is depicted in Fig. 1. Of the 94 eligible patients, three patients were excluded because of patient refusal and the applied exclusion criteria. Five patients were excluded from analysis because of surgery conversion to open thoracotomy or the catheter accidentally slipping out during follow-up. Consequently, 86 patients completed the study. There were no 
Lai J, et al.

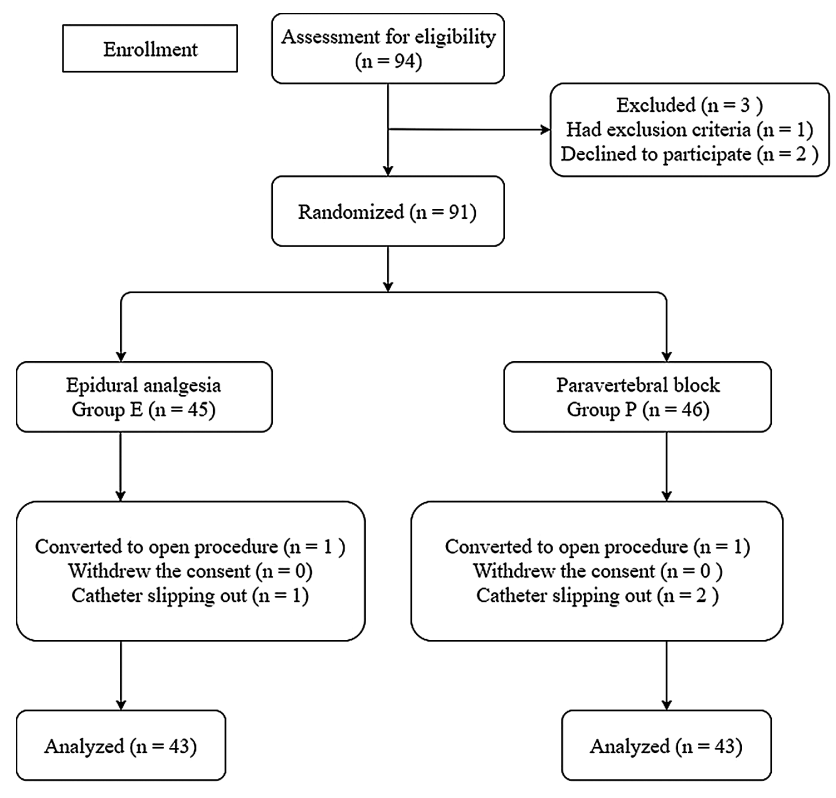

Fig. 1 Flowchart of patient enrollment

significant differences between the two groups in terms of demographics (Table 1).

The comparative analysis of pain using GLM demonstrated slight intergroup differences. The $\mathrm{U}$ test showed significant differences in pain at $24 \mathrm{~h}$ at rest and on coughing $(P=0.001$ and $P<0.001$, respectively) and at $48 \mathrm{~h}$ at rest and on cough $(P=0.004$ and $P<0.001$, respectively). There were no differences between the two groups at other time points (Figs. 2 and $\mathbf{3}$ ).

There were no differences in the duration of drain placement, length of hospital stay, or length of ICU stay between the two groups $(P>0.05)$. Four patients suffered from pulmonary complications in group $\mathrm{P}$, while two patients in group E suffered from pulmonary complications $(P>0.05)$, as shown in Table 2. One patient died in group $\mathrm{E}$.

At $24 \mathrm{~h}$ postoperatively, the incidence rates of adverse events were significantly higher in group $E$ than in group $\mathrm{P}$ (vomiting $32.6 \%$ in group $\mathrm{E}$ vs. $11.6 \%$ in group $\mathrm{P}$, $P=0.019$; pruritus $27.9 \%$ in group E vs. $2.3 \%$ in group $\mathrm{P}, P=0.002$; hypotension $32.6 \%$ in group $\mathrm{E}$ vs. $4.7 \%$ in group $\mathrm{P}, P=0.002$; dizziness $55.8 \%$ in group $\mathrm{E}$ vs. $12.9 \%$ in group $\mathrm{P}, P=0.009)$. The patients in group $\mathrm{P}$ received more cumulative oxycodone doses than those in group $\mathrm{E}$. Although the incidence of adverse events was higher in group $\mathrm{E}$, the patients reported higher satisfaction in group $\mathrm{E}(P=0.047)$. At $48 \mathrm{~h}$ postoperatively, the incidence rates of adverse events, cumulative oxycodone dose, and patient satisfaction were not different between the two groups $(P>0.05)$ (Table 2).
Table 1 Demographic comparison of study groups

\begin{tabular}{|c|c|c|c|}
\hline Parameter & $\begin{array}{l}\text { Group E } \\
(n=43)\end{array}$ & $\begin{array}{l}\text { Group P } \\
(\mathrm{n}=43)\end{array}$ & $P$ value \\
\hline Age (years) & $57 \pm 9$ & $59 \pm 9$ & 0.245 \\
\hline Sex (female, \%) & $20(46.5)$ & $16(37.2)$ & 0.382 \\
\hline Height $(\mathrm{cm})$ & $164 \pm 7$ & $163 \pm 7$ & 0.766 \\
\hline Weight (kg) & $59.6 \pm 8.4$ & $60.5 \pm 9.5$ & 0.666 \\
\hline BMI $\left(\mathrm{kg} / \mathrm{m}^{2}\right)$ & $22.2 \pm 2.4$ & $22.6 \pm 2.8$ & 0.463 \\
\hline $\begin{array}{l}\text { ASA physical } \\
\text { status (I/II/III) }\end{array}$ & $2 / 41 / 0$ & $4 / 38 / 1$ & 0.411 \\
\hline \multicolumn{4}{|l|}{ Lung function } \\
\hline FVC (L) & $3.29 \pm 0.81$ & $3.31 \pm 0.68$ & 0.907 \\
\hline $\mathrm{FEV}_{1}(\mathrm{~L})$ & $2.69 \pm 0.75$ & $2.57 \pm 0.55$ & 0.388 \\
\hline $\begin{array}{l}\mathrm{FEV}_{1} / \mathrm{FVC} \\
\times 100(\%)\end{array}$ & $80.9 \pm 10.8$ & $82.4 \pm 8.9$ & 0.485 \\
\hline $\begin{array}{l}\text { History of } \\
\text { smoking }\end{array}$ & $19(44.2)$ & $13(30.2)$ & 0.181 \\
\hline $\begin{array}{l}\text { History of } \\
\text { dizziness }\end{array}$ & $2(4.7)$ & 5 (11.6) & 0.433 \\
\hline $\begin{array}{l}\text { History of } \\
\text { hypertension }\end{array}$ & $14(32.6)$ & $9(20.9)$ & 0.223 \\
\hline $\begin{array}{l}\text { History of dia- } \\
\text { betes mellitus }\end{array}$ & $3(7.0)$ & $4(9.3)$ & 1.000 \\
\hline $\begin{array}{l}\text { Duration of } \\
\text { anesthesia (min) }\end{array}$ & $178 \pm 41$ & $185 \pm 42$ & 0.445 \\
\hline $\begin{array}{l}\text { Operation } \\
\text { time }(\min )\end{array}$ & $137 \pm 37$ & $146 \pm 38$ & 0.258 \\
\hline Blood loss & $110 \pm 89$ & $89 \pm 38$ & 0.157 \\
\hline $\begin{array}{l}\text { Total intraop- } \\
\text { erative dose of } \\
\text { remifentanil }\end{array}$ & $583 \pm 203$ & $562 \pm 165$ & 0.566 \\
\hline $\begin{array}{l}\text { Number of } \\
\text { inserted drains }\end{array}$ & & & 0.483 \\
\hline 1 & 3 & 6 & \\
\hline 2 & 40 & 37 & \\
\hline
\end{tabular}

Data are presented as the mean \pm standard deviation or number of patients $(\%)$.

ASA: American Society of Anesthesiologist; BMI: body mass index; $\mathrm{FEV}_{1}$ : forced expiratory volume in $1 \mathrm{~s}$; FVC: forced vital capacity

\section{Discussion}

Our study demonstrated that TEA resulted in lower postoperative pain scores than PVB during the first two postoperative days in patients undergoing VATS lobectomy, which was consistent with the results of Marret et al. ${ }^{17)}$ The results of Kashiwagi et al.'s study conflicted with this evidence. ${ }^{9)}$ In our study, the infusion catheter was inserted beneath the parietal pleura under direct thoracoscopic vision. Some authors believe that continuous PVB using the classical landmark puncture technique is not satisfactorily predictable and effective. ${ }^{18-20)}$ After the separation of pleural adhesions, the integrity of the pleura may be destroyed. It led to the leakage of local 


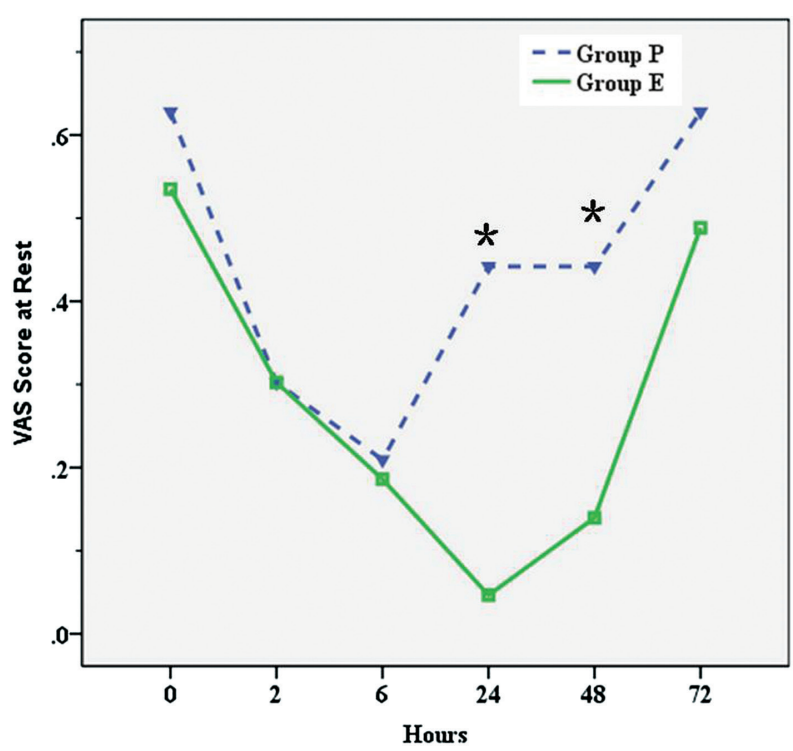

Fig. 2 VAS score at rest 3 at different times. Blue line, group P; green line, group E. *Statistically significant differences. VAS: visual rating scale

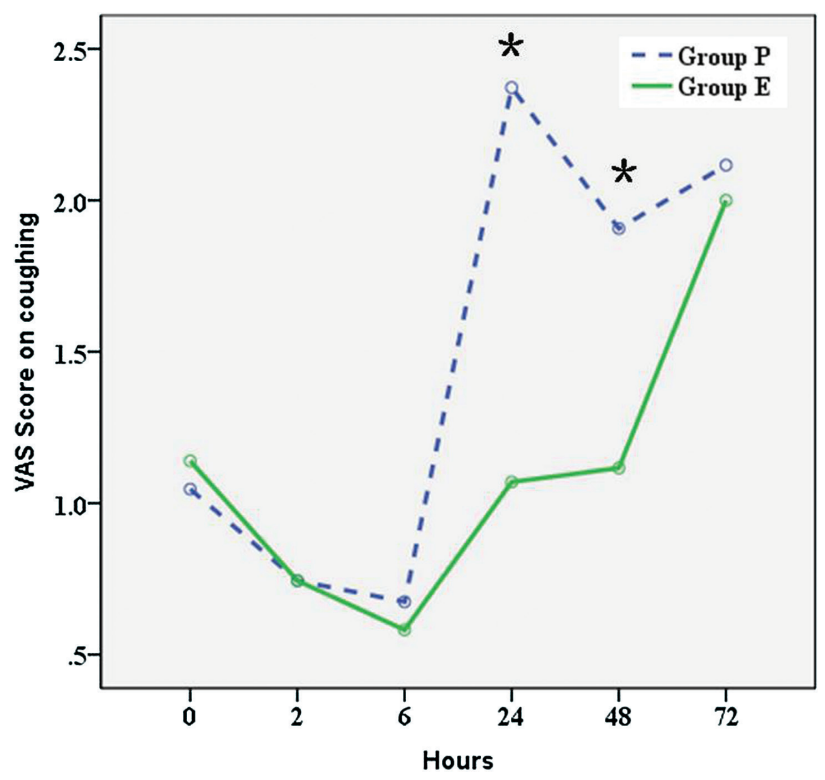

Fig. 3 VAS score on coughing at different times. Blue line, group P; green line, group E. statistically significant differences. VAS: visual rating scale

Table 2 Postoperative data

\begin{tabular}{lccc}
\hline Parameter & $\begin{array}{c}\text { Group E } \\
(\mathrm{n}=43)\end{array}$ & $\begin{array}{c}\text { Group P } \\
(\mathrm{n}=43)\end{array}$ & $P$ value \\
\hline At postoperative $24 \mathrm{~h}$ & & & \\
$\quad$ Nausea & $20(46.5)$ & $12(12.9)$ & 0.074 \\
Vomiting & $14(32.6)$ & $5(11.6)$ & $0.019^{*}$ \\
Pruritus & $12(27.9)$ & $1(2.3)$ & $0.002^{*}$ \\
Hypotension & $14(32.6)$ & $2(4.7)$ & $0.002^{*}$ \\
Dizziness & $24(55.8)$ & $12(12.9)$ & $0.009^{*}$ \\
Cumulative opioid dose (mg) & $4.0 \pm 1.3$ & $8.7 \pm 1.3$ & $0.013^{*}$ \\
Patients satisfaction (1/2/3/4) & $21 / 15 / 7 / 0$ & $11 / 22 / 10 / 0$ & $0.047^{*}$ \\
At postoperative 48 h & & & \\
Nausea & $7(16.3)$ & $3(7.0)$ & 0.313 \\
$\quad$ Vomiting & $3(7.0)$ & $1(2.3)$ & 0.616 \\
$\quad$ Pruritus & $2(4.7)$ & $0(0.0)$ & 0.494 \\
Hypotension & $3(7.0)$ & $0(0.0)$ & 0.241 \\
$\quad$ Dizziness & $9(20.9)$ & $4(9.3)$ & 0.228 \\
$\quad$ Cumulative opioid dose (mg) & $5.1 \pm 2.1$ & $5.3 \pm 1.0$ & 0.904 \\
$\quad$ Patients satisfaction (1/2/3/4) & $24 / 15 / 4 / 0$ & $15 / 23 / 5 / 0$ & 0.078 \\
Duration of drain placement (hours) & $67.5 \pm 36.4$ & $66.2 \pm 40.2$ & 0.878 \\
Length of hospital stay (days) & $11.3 \pm 3.3$ & $11.7 \pm 3.7$ & 0.541 \\
Length of ICU stay (days) & $1.2 \pm 0.7$ & $1.5 \pm 1.2$ & 0.192 \\
Pulmonary complications & $4(9.3)$ & $2(4.7)$ & 0.676 \\
Death & $1(2.3)$ & $0(0.0)$ & 1.000 \\
\hline Da & & &
\end{tabular}

Data are presented as the mean \pm standard deviation or number of patients $(\%)$.

*Statistically significant differences.

ICU: intensive care unit

anesthetics into the chest and resulted in poor analgesic effect. VAS at $2 \mathrm{~h}, 6 \mathrm{~h}$, and $72 \mathrm{~h}$, at rest or on coughing, showed no significant differences between the two groups. Less cumulative opioid doses were needed when patients received postoperative epidural analgesia. This was similar to some previous studies. ${ }^{7,9)}$ 
Lai J, et al.

Currently, enhanced recovery after surgery (ERAS) protocols raise the importance of a multimodal drug regimen associated with peripheral nerve blockade to obtain the best pain relief. ${ }^{21)} \mathrm{PVB}$ is an effective technique with few adverse effects. PVB has been reported as an alternative to TEA. ${ }^{22-24)}$ Compared with TEA, PVB is associated with a lower risk of urinary retention and a lower hypotension effect. ${ }^{22,25)}$ Our results showed that the incidence of vomiting, pruritus, dizziness, and hypotension in PVB group was lower than that in TEA group at 24 hours after operation. These results were consistent with other studies. ${ }^{26)}$ However, there was no difference in the incidence of complications between the two groups at 48 hours after operation. Although the incidence of complications in TEA group was higher, the overall satisfaction of patients was higher in TEA group, which might be related to the better analgesic effect of TEA. This suggested that TEA may be superior to PVB in patients undergoing thoracoscopic lobectomy. Although previous studies have demonstrated a reduction in the hospital stay length when TEA is incorporated into the analgesic plan, ${ }^{27,28)}$ the length of hospital stay, and ICU stay were similar in the two groups in our study. Hospital stay relied on various factors that might depend on postoperative complication occurrence. In our study, there were no differences in pulmonary complications between the two groups.

Several limitations need to be addressed. First, blinding was not performed because it seemed neither feasible nor realistic for this study. Another limitation was the lack of confirmation of complete and accurate positioning of the paravertebral catheter because any catheter mispositioning or plural leakage could affect the results. ${ }^{29)}$ In our study, we did not evaluate postoperative urinary retention. This is because the urinary tube stayed until $48 \mathrm{~h}$ postoperatively. Although cases with severe pleural adhesion were excluded from our study, some patients with mild to moderate pleural adhesion were enrolled in the paravertebral group. We speculated that there might be a higher chance of small pleura tearing during adhesiolysis, which could be an explanation for that.

\section{Conclusion}

Though TEA has more adverse events than PVB, it is more analgesic effective than PVB in patients undergoing VATS lobectomy. TEA may be superior to PVB in patients undergoing thoracoscopic lobectomy.

\section{Ethical Approval}

The study was approved by Sun Yat-sen University Cancer Center Institutional Review Board.

\section{Author Contribution Statement}

Study design and planning: Lai renchun, Long hao, Lai jielan and Situ dongrong; Study conduct: Lai jielan and Situ dongrong; Data analysis: Xie manxiu and Wang junchao, Writing of the paper: Lai jielan and Lai renchun, Revising paper: all authors.

\section{Disclosure Statement}

All authors have no conflict of interests to declare.

\section{References}

1) Bendixen M, Jørgensen OD, Kronborg C, et al. Postoperative pain and quality of life after lobectomy via video-assisted thoracoscopic surgery or anterolateral thoracotomy for early stage lung cancer: a randomised controlled trial. Lancet Oncol 2016; 17: 836-44.

2) Passlick B, Born C, Sienel W, et al. Incidence of chronic pain after minimal-invasive surgery for spontaneous pneumothorax. Eur J Cardiothorac Surg 2001; 19: 355-58 discussion 358-59.

3) Hutter J, Miller K, Moritz E. Chronic sequels after thoracoscopic procedures for benign diseases. Eur $\mathrm{J}$ Cardiothorac Surg 2000; 17: 687-90.

4) Joshi GP, Bonnet F, Shah R, et al. A systematic review of randomized trials evaluating regional techniques for postthoracotomy analgesia. Anesth Analg 2008; 107: $1026-40$.

5) Vogt A, Stieger DS, Theurillat C, et al. Singleinjection thoracic paravertebral block for postoperative pain treatment after thoracoscopic surgery. $\mathrm{Br} \mathrm{J}$ Anaesth 2005; 95: 816-21.

6) Kaya FN, Turker G, Mogol EB, et al. Thoracic paravertebral block for video-assisted thoracoscopic surgery: single injection versus multiple injections. J Cardiothorac Vasc Anesth 2012; 26: 90-4.

7) Helms O, Mariano J, Hentz JG, et al. Intra-operative paravertebral block for postoperative analgesia in thoracotomy patients: a randomized, double-blind, placebo-controlled study. Eur J Cardiothorac Surg 2011; 40: 902-6.

8) Kosi ski S, Fry lewicz E, Wiłkoj M, et al. Comparison of continuous epidural block and continuous paravertebral block in postoperative analgaesia after video-assisted thoracoscopic surgery lobectomy: a randomised, non-inferiority trial. Anaesthesiol Intensive Ther 2016; 48: 280-7. 
9) Kashiwagi Y, Iida T, Kunisawa $T$, et al. Efficacy of ultrasound-guided thoracic paravertebral block compared with the epidural analgesia in patients undergoing video-assisted thoracoscopic surgery. Masui 2015; 64: 1010-4. (in Japanese)

10) Eason MJ, Wyatt R. Paravertebral thoracic block-a reappraisal. Anaesthesia 1979; 34: 638-42.

11) Bimston DN, McGee JP, Liptay MJ, et al. Continuous paravertebral extrapleural infusion for postthoracotomy pain management. Surgery 1999; 126: 650-6 discussion 656-7.

12) Hutchins J, Sanchez J, Andrade R, et al. Ultrasound-guided paravertebral catheter versus intercostal blocks for postoperative pain control in video-assisted thoracoscopic surgery: a prospective randomized trial. J Cardiothorac Vasc Anesth 2017; 31: 458-63.

13) Marret E, Bazelly B, Taylor G, et al. Paravertebral block with ropivacaine $0.5 \%$ versus systemic analgesia for pain relief after thoracotomy. Ann Thorac Surg 2005; 79: 2109-13.

14) Yamauchi $Y$, Isaka $M$, Ando $K$, et al. Continuous paravertebral block using a thoracoscopic catheter-insertion technique for postoperative pain after thoracotomy: a retrospective case-control study. J Cardiothorac Surg 2017; 12: 5 .

15) Long H, Tan Q, Luo Q, et al. Thoracoscopic surgery versus thoracotomy for lung cancer: short-term outcomes of a randomized trial. Ann Thorac Surg 2018; 105: 386-92.

16) Fibla JJ, Molins L, Mier JM, et al. The efficacy of paravertebral block using a catheter technique for postoperative analgesia in thoracoscopic surgery: a randomized trial. Eur J Cardiothorac Surg 2011; 40: 907-11.

17) Marret E, Bazelly B, Taylor G, et al. Paravertebral block with ropivacaine $0.5 \%$ versus systemic analgesia for pain relief after thoracotomy. Ann Thorac Surg 2005; 79: 2109-13.

18) Luyet C, Siegenthaler A, Szucs-Farkas Z, et al. The location of paravertebral catheters placed using the landmark technique. Anaesthesia 2012; 67: 1321-6.

19) Marhofer P, Kettner SC, Hajbok L, et al. Lateral ultrasound-guided paravertebral blockade: an anatomical-based description of a new technique. $\mathrm{Br} \mathrm{J}$ Anaesth 2010; 105: 526-32.
20) Cowie B, McGlade $D$, Ivanusic $J$, et al. Ultrasound-guided thoracic paravertebral blockade: a cadaveric study. Anesth Analg 2010; 110: 1735-9.

21) Beverly A, Kaye AD, Ljungqvist $O$, et al. Essential elements of multimodal analgesia in enhanced recovery after surgery (ERAS) guidelines. Anesthesiol Clin 2017; 35: e115-e143.

22) Davies RG, Myles PS, Graham JM. A comparison of the analgesic efficacy and side-effects of paravertebral vs epidural blockade for thoracotomy--a systematic review and meta-analysis of randomized trials. $\mathrm{Br} \mathrm{J}$ Anaesth 2006; 96: 418-26.

23) Komatsu $T$, Kino $A$, Inoue $M$, et al. Paravertebral block for video-assisted thoracoscopic surgery: analgesic effectiveness and role in fast-track surgery. Int $\mathbf{J}$ Surg 2014; 12: 936-9.

24) Komatsu T, Sowa T, Takahashi K, et al. Paravertebral block as a promising analgesic modality for managing post-thoracotomy pain. Ann Thorac Cardiovasc Surg 2014; 20: 113-6.

25) Joshi GP, Bonnet F, Shah R, et al. A systematic review of randomized trials evaluating regional techniques for postthoracotomy analgesia. Anesth Analg 2008; 107: 1026-40.

26) Zejun N, Wei F, Lin L, et al. Improvement of recovery parameters using patient-controlled epidural analgesia for video-assisted thoracoscopic surgery lobectomy in enhanced recovery after surgery: A prospective, randomized single center study. Thorac Cancer 2018; 9: 1174-9.

27) Nishimori M, Low JH, Zheng H, et al. Epidural pain relief versus systemic opioid-based pain relief for abdominal aortic surgery. Cochrane Database Syst Rev 2012; 7: CD005059.

28) Pöpping DM, Elia N, Marret E, et al. Protective effects of epidural analgesia on pulmonary complications after abdominal and thoracic surgery: a metaanalysis. Arch Surg 2008; 143: 990-9; discussion 1000.

29) Jung J, Park SY, Haam S. Efficacy of subpleural continuous infusion of local anesthetics after thoracoscopic pulmonary resection for primary lung cancer compared to intravenous patient-controlled analgesia. J Thorac Dis 2016; 8: 1814-9. 